\title{
Mother to daughter transmission of Female Genital Cutting in Egypt, Burkina Faso and Senegal
}

\author{
Patrizia Farina*1 and Livia Elisa Ortensi ${ }^{2}$ \\ ${ }^{1}$ Department of Sociology and Social research, University of Milan - Bicocca. Piazza dell'Ateneo \\ Nuovo, 1 - 20126. Milan Italy Telephone +39.02 .64485843$ \\ Email: patrizia.farina@unimib.it \\ ${ }^{2}$ Department of Sociology and Social research, University of Milan - Bicocca \\ Email: livia.ortensi@gmail.com
}

\begin{abstract}
The aim of article is to assess the determinants of mothers to daughters transmission of female genital cutting (FGC) in Senegal, Burkina Faso and Egypt. Using the most recent DHS surveys the study confirms that the main dimension related to daughters' circumcision is mother's personal experience as circumcised mothers more likely to perpetrate the practice on daughters. Policies aim at changing this social norm could therefore generate a virtuous circle: for each child who is not circumcised, a risk-free third-generation is projected. Factors related to women's empowerment as better education, higher autonomy and wealth of the family as well social environment against FGC also discourage the continuation of the practice and protect daughters from the risk to be circumcised in each country analyzed.
\end{abstract}

Keywords: female genital cutting, empowerment

\section{Résumé}

Le but de l'article est d'évaluer les facteurs déterminants de la transmission de la mutilation génitale féminine (MGF) entre mères et filles en Sénégal, en Burkina Faso et en Egypte. Selon les plus récents sondages du 'Démographique et de Santé', l'étude confirme que le facteur principal lié à la mutilation des filles est l'expérience personnelle de la mère car il est plus probable que les mères excisées vont pratiquer l'excision sur leurs filles. Des politiques visés à changer cette habitude sociale pourraient donc générer un cercle vertueux: pour chaque enfant qui ne vient pas mutilé, on envisage une troisième génération sans risque. Les facteurs liés à l'émancipation des femmes tels le niveau d'instruction, une plus grande autonomie et le niveau économique de la famille, plus le mouvement social contre la mutilation génitale féminine (MGF) aident à décourager la continuation de ce pratique et à protéger les filles du danger d'excision dans chacun des pays pris en considération.

Mots clé: mutilation génitale féminine, émancipation 


\section{Introduction}

Over the last decade Female genital cutting (FGC) has been at the center of international debate in terms of human rights protection and the safeguard of women's health. This attention has resulted in concrete actions aimed at eliminating FGC: international conventions and treaties have been ratified and national government initiatives have been implemented to prohibit the practice and build political action in favor of its abandonment. These domestic and international actions have resulted in an actual decline in FGC among younger generations, but not everywhere and not with the same intensity.

This paper discusses and examines the importance of some of the factors that favor the continuation of this practice by investigating the parties involved and the social environment in which they live. In particular, we will verify and assess the importance of the personal experience of mothers and their empowerment, the role of stakeholders and religious leaders, and from a social standpoint, the importance of the cultural value assigned to FGC and dissemination of the practice. Identifying and evaluating the significance of these factors forms a basis for the implementation of appropriate policies and measures aimed at reducing FGC on young children.

Female Genital Cutting: definition and diffusion.

Female Genital Cutting (FGC) also known as "female genital mutilation" or "female circumcision"', refers to all practices involving the partial or total removal of the external female genitalia or other injury to the female genital organs for non-medical reasons. This first general definition of FGC refers to a broad range of practices that may greatly vary among ethnic groups or according to different places of residence (Yoder et al., 2004). An internationally accepted typology developed in 1995 by the World Health Organization and updated in 2007 identifies four main types of practices ranging from the partial or total removal of the clitoris to infibulation, and including other type of modification like stretching, cauterization and piercing etc. (WHO, 2008; Unicef, 20I3). FGC is currently quite common in Africa and the Middle East, spanning at least 29 countries and affecting more than 125 million girls and women (Unicef, 2013). Evidence suggests that the practice also exists in other countries such as Colombia, Jordan, Oman, Saudi Arabia and parts of Indonesia and Malaysia, and among groups of migrants in Europe and North
America (e.g. Population Council, 2003; UNPFA 201 I; Andro et al., 2009; Farina, 20 I0; Nour, 2005).

All forms of FGC are considered to be violations of the human rights of children and women. On 20 December 2012, the UN General Assembly adopted a first-ever resolution against FGC, defining it as "an irreparable, irreversible abuse that impacts negatively on the human rights of women and girls" and reaffirmed "that female genital mutilations are a harmful practice that constitutes a serious threat to the health of women and girls [...] and that the abandonment of this harmful practice can be achieved as a result of a comprehensive movement that involves all public and private stakeholders in society" (UN General Assembly, 2012: 2). Before this act the issue of FGC was addressed by the 1993 Vienna World Conference on Human Rights that classified FGC as a form of violence against women and by the 2003 'Maputo Protocol' that went into effect in 2005 (Shell-Duncan, 2008). Many countries have taken steps to eliminate the practice through educational programs as well as law enforcement against FGC (Tostan, 1999; Unicef-IRC, 2010). In most African countries penalties range from a minimum of three months to a maximum of life in prison and many impose monetary fines (Leye et al, 2007; WHO, 2008).

\section{Theoretical framework and Literature review}

FGC has been successfully framed from a social norms perspective. According to this approach, the practice can be considered a social norm (Bicchieri, 2005) if individuals are aware of the rules of behavior regarding the circumcision of girls and still conform to the practice because they expect that a sufficiently large segment of their social or reference group (e.g. ethnic or religious) will consider FGC as compulsory. They also expect that members of their reference group will accordingly cut their daughters and may sanction them if they do not conform. As FGC is held in place by reciprocal expectations, it is difficult for isolated individuals to autonomously abandon the practice, as compliance with a social convention is considered to be in an individual's best interest. Failure to conform to FGC can also lead to criticism, social exclusion, stigma and the daughters' exclusion from the marriage market (Unicef-IRC, 2010; Unicef, 2013). On the contrary, the existence of a growing number of families who are abandoning the practice will lead other families in the intramarrying communities ${ }^{2}$ to follow their example. When the greater part of the community is persuaded to abandon FGC, a "tipping point" is reached and the abandonment will become stable as 
a consequence of a permanent change in social expectations. Community members would now be expected not to cut their daughters and would be socially rewarded or sanctioned accordingly (Mackie and Le Jeune, 2009; Unicef, 2013; Innocenti-IRC, 2005).

The rise of a critical mass, a number of people that is large enough to launch a process of ongoing group change, which publicly stands up against a social norm, facilitates the revision of beliefs on the basis of new information, public declaration and other manifestations of commitment to a new social rule. This is a fundamental passage of the Convention Theory (Mackie, 2000; Mackie and Lejeune, 2009). This theorization proved to be useful in promoting holistic and community-based programs, while incorporating human rights deliberation. Community-led programs are now identified as a necessary factor to tackle the social convention of FGC, and evaluations of interventions suggest that community involvement is key in creating an environment that enables and supports sustainable change (Mackie and Lejeune, 2009; Unicef, 2013; Unicef-IRC, 2010). Although the strength of the results varies between communities, examples of this approach are found in countries included in our analysis as well, with overall positive outcomes (Johansen et al, 20I3). In Egypt, efforts at campaigning against FGC began in 1920 and have continued, passing through various phases (Denniston et al., 1999). Campaigns based on this holistic approach have been active since 2003. The most notable example is 'The FGM-Free Village Model', a national project designed to empower girls and their families to make a well-informed, sound choice to abandon FGC. The project aim was to eliminate social pressure on women, targeting all community members in 120 villages throughout Upper and Lower Egypt. The main components of this projects included: capacity building of local NGOs, empowerment of the so-called 'positive deviants', cooperation with community leaders, interventions to raise community awareness, dialogue on FGC and other issues (hygiene education, rights, and parental education) and the monitoring and tracking of girls at risk of FGC and their families. Evaluation reports show that these campaigns generally had good results in changing views and attitudes toward FGC among respondents in the intervention groups (Population Council, 2011; CEPDA, 2004; McCloud, 2003). In Senegal the Tostan Community Empowerment Program took a holistic approach to development by facilitating a human rights-based, "non-formal" education program. The approach was similar to the FGM-Free Village Model including community-wide public declarations and the engagement of traditional and religious leaders as agents of change, and was able to bring about social change by reducing support for FGC and its practice, while also making gains in child protection, the empowerment of women and girls and early childhood development (Population Council et al, 2004; Gillespie and Melching, 2010). The link with Convention Theory was specifically cited in this project, even though it appears as an ex post facto reflection (Berg and Denison, 2013). The same model was replicated in Burkina Faso: public discussion of FGC lead to a change in traditional social norms resulting in an increased awareness of human rights and women's health, and reduced support for FGC (Population Council and Frontiers in Reproductive Health, 2005). On the contrary, actions targeting traditional practitioners or health care professionals have not proved to be effective, perhaps due to a lack of theoretical or empirically tested sociological model informing these strategies (Diop and Askew, 2006). Consistent with this framework, previous quantitative research has shown evidence of community effects such as ethnic composition and proportion of cut women within each community, on the mother to daughter continuation of FGC (Hayford, 2005).

Two other successful approaches to the analysis of FGC continuation are the Modernization Theory and the Feminist Theory (Yount, 2002).

The Modernization theory states that the transition from an agricultural to a modern and developed economy changes social conditions, thereby affecting the prevalence of FGC since it reduces family control over individuals, leads to the erosion of ties to family or ethnic group, and increases perceived individual rights over social responsibilities and obligations (Boyle et al., 2002; Hayes, 1975).

Instead Feminist theorists of FGC focus on women's status as the most important component of social change. As women's statuses and level of empowerment grow, dependence upon their families and husbands declines. Accordingly, taking decisions about their daughters' bodies becomes easier. Moreover, the importance of FGC as a prerequisite to entering the marriage market may become less relevant (Althaus, 1997; Yount, 2002). These approaches are not in contrast; in fact, as stated above, results from campaigns against FGC 
show that directly supporting broader goals such as reducing gender inequality and violence against girls and women promotes and contributes to the abandonment of other harmful practices (UnicefIRC, 20I0). Studies confirm that the characteristics of mothers exposed to female empowerment have proven to be significant: educated women are less likely to circumcise their daughters and urban women are less likely to support and consequently perpetuate the practice (e.g. Dorkenoo and Elworthy, 2006; Hayford, 2005; Boyle et al. 2002; Yount, 2002; Afifi, 2009; El Gibaly, 2002; Dalal, 20I0).

Religion plays an important role. Female circumcision was practiced at the dawn of Egyptian civilization and most probably evolved in subSaharan Africa millennia earlier (Shell-Duncan and Hernlund, 2000; Caldwell, and Caldwell, 1993). Therefore it cannot be considered a practice related to Islam. However, some studies show that daughters of Muslim women have a significantly higher risk of being circumcised than daughters of Christians or mothers of other religions. Interpretations on this issue are controversial: in certain research this relationship is attributed to the mere overlapping of ethnicity and the Islamic religion (Unicef, 2005). Other scholars instead have hypothesized a direct link by stating, for example, that Christianity is more closely linked to individualism and the ideology of individual rights than many other religions. On these grounds, they suggest that a connection exists between Christianity and opposition to FGC (Boyle et al, 2002). Other hypotheses suggest the relevance of a collective rather than individual Muslim identity for the continuation of the practice (Hayford and Trinitapoli, 20II). A 'true' Islamic position on FGC appears impossible to identify given that those involved argue from their own interpretation of the written sources (Berg and Denison, 2013) and Islamic law schools manifest differently according to socio-cultural practices in their respective countries (Roald, 200I).

In this study we have built upon this theoretical framework to analyze the patterns of FGC transition to daughters in Egypt, Burkina Faso and Senegal.

The operationalization of these aspects and the role played by each covariate in the two groups of models will be explained in the next section.

\section{Data and Methods}

Data

The design of the surveys, the specific questions that were covered and their limitations are detailed in each country report (El-Zanaty and Way, 2009; INSD and ICF International, 20I2; ANSD and ICF International, 20I2).

For the purposes of this paper, the analysis was restricted to a sub-sample of the daughters (as reported in the Birth Recode Format and regardless of their residence at the time of the interview) and their mothers. To mitigate the effects of recall bias and censoring on the part of the mothers in remembering and reporting the experience of their daughters, the sample was narrowed to include daughters aged $0-19$ years at the time of the survey. The final analysis involved a sample of 18,276 daughters and 10,757 mothers for Egypt, 18,276 and 10,725 mothers and daughters for Burkina Faso and 16,130 and 8,181 mothers and daughters for Senegal.

Methods

To analyze the children's female genital cutting experience (the dependent variable) and the age at which the cutting took place, a Multilevel Event History approach was implemented. As the time at which the cutting happened is expressed in term of the daughter's age, there are only a few possible survival times shared by many subjects and a discrete time survival model was needed. Moreover, as our data has a hierarchical structure, with daughters nested in mothers, we have used a multilevel discrete-time survival model where random effects (or frailties) are included to handle unobserved heterogeneity between clusters and within clusters dependence. The final model is a random intercept complementary log-log model.

$$
\begin{aligned}
\ln \left\{-\ln \left(1-h_{s i j}\right)\right\} & \\
& =\alpha_{1} d_{1 s i j}+\cdots+\alpha_{n} d_{n i j}+\beta_{2} x_{2 i j} \\
& +\cdots+\beta_{r n} x_{r i j}+\zeta_{j}
\end{aligned}
$$

Where $\zeta_{j} \sim N(0, \psi)$ and the random intercepts are independent from the covariates. The exponentiated random intercept $\exp \left(\zeta_{j}\right)$ represents a shared frailty in terms of a mother or family-specific disposition toward female genital cutting that is shared among daughters nested in the same family.

By using dummy variables for the time intervals, we are not making any assumption regarding the shape of the discrete time hazard function.

The reported value $\rho=\frac{\widehat{\psi}}{\widehat{\psi}+\frac{\pi^{2}}{6}}$ represents the estimated residual correlation among the latent 
responses for two daughters of the same mother and measures the dependence among FGC survival times for children of the same mother after controlling for the observed covariates.

Two different models have been fitted on each country dataset. The first uses the entire sample while the second includes only daughters of circumcised mothers in order to analyze more precisely the process of discontinuation by circumcised women who are generally more willing to preserve it.

\section{Measures}

Several socio-economic and cultural key explanatory variables were included in the analysis to explain the differences in mother to daughter continuation of FGC and in accordance with the theoretical framework. We have included certain socio-economic variables related to the modernization theory to account for the mother's and daughter's family of origin, including: type of place of residence (V025) and a wealth index (V190).

Then we included some variables as operationalization of mechanisms stemming from feminist theory. An indicator was built to explain the gap in female autonomy within couples' relations ${ }^{3}$. This indicator is a combination of two existing item sets. The first set is about decision making within the couple or the family, and expresses autonomy and co-responsibility in managing the family, including who has the final say on the respondent's health, on making large household purchases, on the possibility of visiting family or relatives and on deciding how to spend money (V743A-V743F). Each variable has been recoded 0 if the respondent takes decisions alone or with someone (autonomy), otherwise I. The second set of items reports the women's opinions about the acceptability of intimate partner violence under certain circumstances. The justification women give about the possibility of being beaten is considered to be a disadvantage. Five dummy variables stating whether respondents agree that wife beating is justified if she goes out without telling him, she neglects the children, she argues with him, she refuses to have sex with him, or she burns the food (V744A-V744E) have been added. The final variable, "gender gap", takes these two dimensions into account and has been recoded into three levels according to the "degree of autonomy" and "legitimacy of violence". For similar reasons we have included the mother's education in years (VI33) and her age at first marriage (V5II). In fact the literature proves that women who marry at a young age tend to be less educated, start childrearing earlier and have less decision-making power in the household. (Jensen and Thornton, 2003). We expect daughters born to women who married early to be at a higher risk for FGC.

The Convention theory was operationalized by including a variable accounting for the estimated prevalence of daughters who were cut by the normative age (UNICEF, 20I3) in the primary sampling unitof residence. This variable accounts for the existence of a group of so-called "positive deviants" that may motivate other women not to cut their daughters.

Information about the mother's religion was also incorporated (VI30).

Finally, information on the daughter's birth order and year of birth (B2) has been used to control for general changes over the years.

Before illustrating the main results of the analysis some limitations must be highlighted. First of all, we are dealing with self-reported data that need to be treated with caution in case they have been subject to recall bias, especially for elder daughters, or voluntary underreporting. It is crucial to consider the context in which questions about FGC status are being asked: if FGC is widespread, socially acceptable and there are no well-publicized interventions causing people to question its acceptability and legality, then self-reporting is likely to be valid. On the contrary, in a setting where any one of these conditions is not present, women may be unwilling to report having undergone the procedure for fear of being stigmatized or for the illegal status of the practice (Askew, 2005). In our study this might have been the case for Burkina Faso, where it has been emphasized that part of the reduction in the reported prevalence on daughters may be due to voluntary underreporting (Diop et al., 2008).

Another limitation is that we treat circumcision as a decision made by women alone even if husbands and other family members, especially mothers-in-law, may play an important role (ShellDuncan et al. 2000; Yount 2002; Hayford, 2005). This choice is necessitated by the structure of the DHS data, which is collected from women and includes limited information about other household members.

The analysis is also limited by the fact that we have little information about each daughter, their mother and families of origin at the time of each circumcision. Additionally, information about FGC prevalence in the ethnic group or the dominant ethnicity in each cluster was not included in the 
analysis. Ethnic classification also may be complex in some contexts and difficult to trace in survey data (Unicef, 2013) and was unavailable for Egypt. In Burkina Faso and Senegal the use of ethnicity would have led to the exclusion of many cases labeled as "other" or "foreign".

\section{Results}

\section{Background on Countries}

Our analysis is based on DHS surveys carried out in Egypt (2008 EDHS), Burkina Faso (2010 BDHS), and Senegal (20I0-II SDHS). These countries were selected for different reasons.

First, all three countries have laws against circumcision ${ }^{4}$. Senegal and Burkina Faso instituted their laws back in the nineties and recently followed them up with specific action plans aimed at fighting the practice. The Egyptian law is instead more recent (2008).

The second key aspect concerns FGC prevalence levels across countries and individually. The Unicef classification (2013) places each country into a different group based on prevalence levels. Egypt was chosen from countries with a very high prevalence (more than $80 \%$ ). Burkina is among countries with a moderately high prevalence (50$80 \%$ ) while Senegal has a moderately low prevalence (from 26 to $50 \%$ ) and the practice is confined to communities concentrated in specific regions. This difference among countries allows for an analysis of practice continuation in cultural and social contexts with a different social support towards FGC.

A third key aspect concerns the different degrees of economic and social development across countries. The Gross domestic product (GDP) of Egypt is three times higher than that of Burkina Faso and the percentage of the population living on less than US\$ 1.25 a day is only approximately $2 \%$ compared to $45 \%$ in Burkina. Senegal represents an intermediate standard of living, but its profile is closer to that of other Sub-Saharan countries (UNDP, 2012).

Finally, the three countries have carried out investigations in relatively recent years (between 2008 and $20 \mathrm{II}$ ) so that circumcision status and age at cutting is available for all daughters and the samples are populated by an appropriate number of mothers and daughters.

\section{Sample characteristics}

The majority of mothers and daughters included in the samples live in rural areas with the highest concentration in Burkina Faso. In the two subSaharan African countries mothers have an average age between 32 and 34, very low education levels and a high illiteracy rate. In Egypt the illiteracy rate is less than $30 \%$ and a large proportion of females have a secondary education.

FGC is very high among the mothers in Egypt and Burkina ( $94.5 \%$ and $82.5 \%$ respectively) and much less so among the Senegalese who, however, show a higher incidence of having their genital areas sewn closed ${ }^{5}$. 
Table I. Characteristics of mothers and daughters aged 0-19 at the time of the survey included in the samples. Egypt, Senegal and Burkina Faso

\begin{tabular}{|c|c|c|c|}
\hline & Egypt & Burkina Faso & Senegal \\
\hline \multicolumn{4}{|l|}{ Daughters' characteristics } \\
\hline Mean age at the survey & 8,7 & 7,9 & 7,5 \\
\hline Mean age at circumcision & 8,5 & 3,0 & 1,3 \\
\hline Proportion of daughters aged $0-5$ circumcised & 2,3 & 4,1 & 10,6 \\
\hline Proportion of daughters aged I5-19 circumcised & 75,9 & 20,1 & 13,2 \\
\hline Proportion of daughters aged $0-19$ circumcised & 30,0 & 11,8 & 13,6 \\
\hline$\%$ living in rural areas & 62,3 & 78,0 & 69,3 \\
\hline \multicolumn{4}{|l|}{ Mothers' characteristics } \\
\hline Mean age at the survey & 34,2 & 32,7 & 32,1 \\
\hline Mean age at marriage/first cohabitation & 19,4 & 17,6 & 17,6 \\
\hline \multicolumn{4}{|l|}{ Religion } \\
\hline Muslim & 95,4 & 61,1 & 96,0 \\
\hline Christian & 4,6 & 28,4 & 3,3 \\
\hline Other/No Religion & NA & 10,5 & 0,7 \\
\hline \% illiterate & 35,1 & 83,2 & 75,6 \\
\hline$\%$ graduated & 9,7 & 0,3 & 0,4 \\
\hline \% circumcised & 94,5 & 82,5 & 57,4 \\
\hline$\%$ with Genital Area Sewn Closed & NA & $\mathrm{I}, \mathrm{I}$ & 13,5 \\
\hline \% living in household with electricity & 95,7 & 10,7 & 43,4 \\
\hline$\%$ with living in an accommodation with water piped into dwelling & 86,5 & $\mathrm{I}, 7$ & 25,2 \\
\hline \% living in a household with a radio & 67,9 & 72,8 & 74,2 \\
\hline \% living in a household with a television & 91,7 & 14,9 & 42,1 \\
\hline GDP per capita $(\$)^{\circ}$ & 2157 & 593 & 993 \\
\hline
\end{tabular}

Source: Authors' elaborations on EDHS (2008), BDHS (2010), SDHS (2010-II); WorldBank Database http://data.worldbank.org/

As it was pointed out by a large body of recent research and reports (e.g. Yount, 2002; Hayford and Trinitapoli, 20I I; El-Gibaly et al., 2002), the practice is less intense among younger women. This is also evident from our results if we compare the prevalence among daughters aged $15-19$ to the prevalence among mothers ${ }^{6}$.

A significant and relevant aspect of the practice is the age at cutting, which varies widely between countries. The differentiation is very clear considering the age for all of the women interviewed. In Senegal, more than one in four women has been circumcised within the first year of life and $92 \%$ within nine years. In Egypt the age is much higher: more than $90 \%$ of the women have been circumcised after age four, and half between ten and fourteen, as it is often associated with the rites of transition to adolescence.
Daughters' Discrete-Time Hazard and Discrete Time Survival to FGC

The differences between countries are well summarized in the three separate life tables, which estimate the discrete time survival function and the hazard rate calculated on the three groups of daughters ${ }^{7}$. As shown in Figure I, Egyptian girls have a higher risk of experiencing FGC but their "survival of FGC" is higher during the first years of life. The risk of experiencing FGC for Senegalese children is highest at 0 and decreases thereafter while among the daughters of Burkina Faso it is between 2 and 5, and among Egyptian between 10 and 13. Moreover, the shape of the curves of the daughters of circumcised or non-circumcised women is also worth noting. The gap between the curves of Burkina Faso and Egypt respectively is negligible because FGC prevalence in the countries is high. In Senegal the gap is highly significant, because FGC is supported in low prevalence by social norms in the communities where the practice is viewed as a social obligation. 
Figure I Discrete-Time Survival Function to FGC and Discrete-Time Hazard Risk Function of daughters aged 0-19 at the time of the survey according to mother's circumcision status. Senegal, Egypt, Burkina Faso
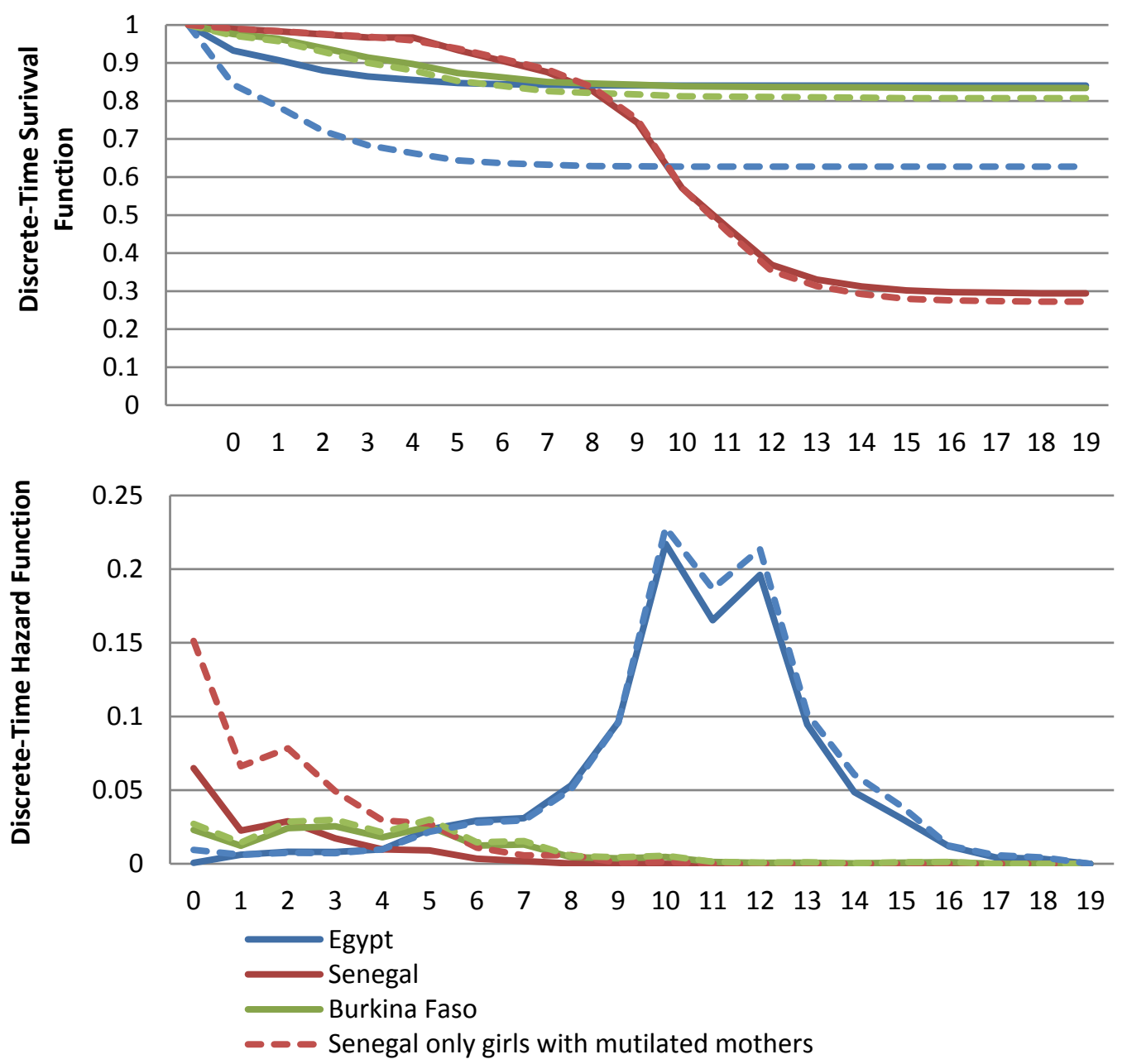

Source: Authors' elaborations on EDHS (2008), BDHS (20 I0), SDHS (20 I0- I I).

\section{Multivariate Analysis}

The study highlights the key characteristics of mothers and daughters that either foster or discourage the continuation of the practice, according two models. Model I and Model 2 contain mostly the same variables however Model 2 only includes the daughters of circumcised mothers in order to more specifically grasp the factors correlated to a mother's discontinuation of the practice. The results are largely consistent with those of the model applied to the full sample.
The most important dimension related to a daughter's circumcision is her mother's experience, especially in Senegal where the prevalence is lower than that of other countries. Controlling for the circumcision experience of the mother is therefore crucial for performing a correct analysis and properly analyzing the other risk factors (Morison et al., 200I). The circumcision status of the mother can be also considered as a proxy of the attitude of the family and of the women's family of origin toward FGC. 
Table 2. Odds ratios from Random Intercept Complementary Log-log model analyses. All Women (Model I); Only daughters of circumcised women (Model 2), Egypt, Senegal, Burkina Faso

\begin{tabular}{|c|c|c|c|c|c|c|}
\hline \multirow[b]{2}{*}{ Covariates } & \multicolumn{3}{|c|}{ Modell } & \multicolumn{3}{|c|}{ Model 2} \\
\hline & Egypt & Senegal & $\begin{array}{l}\text { Burkina } \\
\text { Faso }\end{array}$ & Egypt & Senegal & $\begin{array}{l}\text { Burkina } \\
\text { Faso }\end{array}$ \\
\hline age 0 & $0.123^{*}$ & 4.059 & 1.442 & $0.117 *$ & 3.880 & 1.384 \\
\hline age I & $0.082 *$ & 3.524 & 1.346 & $0.080 *$ & 3.356 & 1.303 \\
\hline age 2 & $0.101^{*}$ & 6.004* & 3.642 & $0.097 *$ & $5.80 I^{*}$ & 3.560 \\
\hline age 3 & 0.098* & $5.115 *$ & 5.198* & 0.095* & 4.902 & 5.070* \\
\hline age 4 & $0.14 I^{*}$ & 3.692 & 4.473* & $0.137 *$ & 3.592 & 4.403* \\
\hline age 5 & $0.34 I$ & 4.244* & 7.728*** & 0.330 & 4.088* & $7.675^{* *}$ \\
\hline age 6 & 0.494 & 2.023 & 4.405* & 0.479 & 1.983 & 4.369* \\
\hline age 7 & 0.589 & I.27I & 5.038* & 0.572 & 1.250 & 5.045* \\
\hline age 8 & $\mathrm{I} .144$ & 1.534 & 1.820 & 1.108 & 1.515 & 1.824 \\
\hline age 9 & 2.672 & 0.247 & 1.539 & 2.598 & 0.244 & 1.543 \\
\hline age 10 & 9.892*** & & 1.998 & 9.648*** & & 2.003 \\
\hline age II & II.223*** & & 0.539 & $\begin{array}{l}11.018 * \\
*\end{array}$ & & 0.540 \\
\hline age 12 & $18.350 * *$ & & 0.321 & $\begin{array}{l}18.028 * \\
*\end{array}$ & & 0.321 \\
\hline age 13 & II.156** & & 0.447 & $\begin{array}{c}10.827 * \\
*\end{array}$ & & 0.448 \\
\hline age 14 & 7.739* & & 0.239 & 7.526* & & 0.240 \\
\hline age 15 & 5.759 & & & 5.725 & & \\
\hline age 16 & 1.889 & & & 1.878 & & \\
\hline age 17 & 1.048 & & & 1.048 & & \\
\hline Daughter's year of birth & $0.917 * * * *$ & $\begin{array}{c}0.866 * * \\
*\end{array}$ & $0.837^{* * * * *}$ & 0.918 **** & $\begin{array}{c}0.866 * * \\
*\end{array}$ & $\begin{array}{c}0.833^{* *} \\
*\end{array}$ \\
\hline Daughter's birth order & $0.919 * * *$ & $\begin{array}{l}0.532 * * \\
*\end{array}$ & $0.652 * * * *$ & $0.919 * * *$ & $\begin{array}{l}0.536 * * \\
*\end{array}$ & $\begin{array}{c}0.66 I^{*} * \\
*\end{array}$ \\
\hline Gender Gap:I medium (Ref. Low) & I.267***** & I.398* & 1.093 & I.263**** & $1.356 *$ & 1.096 \\
\hline Gender Gap:2 high (Ref. Low) & I.223** & $\begin{array}{l}1.702 * * 6 \\
*\end{array}$ & $1.269 *$ & I.229** & $\begin{array}{l}1.634 * * * \\
\quad *\end{array}$ & $1.300 *$ \\
\hline Wealth index: Poorer (ref. Poorest) & 1.004 & 0.922 & 0.974 & 0.998 & 0.965 & 0.922 \\
\hline Wealth index: Middle (ref. Poorest) & 1.008 & 1.085 & 0.805 & 1.003 & 1.113 & 0.937 \\
\hline Wealth index: Richer (ref. Poorest) & 0.858 & 1.014 & 0.899 & 0.852 & 1.023 & 0.777 \\
\hline Wealth index: Richest (ref. Poorest) & 0.864 & 0.676 & $0.675^{*}$ & 0.871 & $0.64 I^{*}$ & $0.644 *$ \\
\hline Education in single years & 0.980 **** & 0.961 & 0.872 ***** & $0.980 * * * *$ & $0,950 *$ & 0.981 \\
\hline Mother's Age at first marriage & $0.974 * * * *$ & $0.972^{*}$ & 0.982 & $0.974 * * * *$ & $0.975^{*}$ & $\begin{array}{c}0.876 * * \\
*\end{array}$ \\
\hline Type of place of residence: Rural (ref. Urban) & $1.114 *$ & I.246* & I.167* & $1.105 *$ & I.288* & $1.162 *$ \\
\hline Religion: Christian (ref. Muslim) & $0.767 *$ & 0.619 & $0.460 * * * *$ & $0.787^{*}$ & 0.529 & $\begin{array}{c}0.454 * * \\
*\end{array}$ \\
\hline Religion: other (ref. Muslim) & 0.889 & 0.702 & 0.829 & 0.890 & 0.734 & 0.855 \\
\hline Mother is circumcised: Yes (ref. No) & $\begin{array}{l}11.970 * * \\
\quad *\end{array}$ & $\begin{array}{l}313.3^{*} * \\
*\end{array}$ & 27.523 **** & - & - & - \\
\hline $\begin{array}{l}\text { Prevalence of FGC in the place of residence: } 50 \% \mid-80 \% \text { (ref. } \\
>80 \% \text { ) }\end{array}$ & $0.177^{* * * * *}$ & 0.830 & $0.239 * * * *$ & $0.175 * * *$ & 0.802 & $\begin{array}{c}0.243^{*} * \\
*\end{array}$ \\
\hline $\begin{array}{l}\text { Prevalence of FGC in the place of residence: } 30 \% \mid-50 \% \text { (ref. } \\
>80 \% \text { ) }\end{array}$ & $0.084 * * * *$ & 0.561 & $0.038 * * *$ & $0.083 * * *$ & 0.560 & $\begin{array}{c}0.037 \text { *** } \\
*\end{array}$ \\
\hline Prevalence of FGC in the place of residence: $0 \% \mid-30 \%$ (ref. $>80 \%$ ) & $0.022 * * * *$ & $\begin{array}{l}0.157^{*} * \\
*\end{array}$ & $0.005 * * * *$ & $0.021 * * * *$ & $\begin{array}{l}0.162 * * \\
*\end{array}$ & $\begin{array}{c}0.005 * * \\
*\end{array}$ \\
\hline Sigma & 0.882 & 1.836 & 2.183 & 0.889 & 1.815 & 2.184 \\
\hline Rho & $0.321^{\circ}$ & $0.672^{\circ}$ & $0.743^{\circ}$ & $0.324^{\circ}$ & $0.667^{\circ}$ & $0.744^{\circ}$ \\
\hline Number of obs & 88756 & 53127 & 124847 & 84521 & 19505 & 104132 \\
\hline Number of groups & 10539 & 6368 & 9902 & 10034 & 2719 & $8|2|$ \\
\hline Log-Likelihood & -10072 & -5219 & -9.099 & -10024 & -5101 & -9322 \\
\hline AIC & 0.228 & 0.198 & 0.146 & 0.238 & 0.527 & 0.180 \\
\hline
\end{tabular}

${ }^{\circ}$ Likelihood-ratio test of rho $=0: p<0.05 * p \leq .05 * * 2 \leq .001 .{ }^{*} * * * 0.0001$

Source: Authors' elaborations on EDHS (2008), BDHS (2010), SDHS (2010-1 I).

The younger generations have a lower risk of cutting when compared to their mothers and even to their older sisters.
The mother's empowerment is also a key aspect. Educated women are less likely to support and perpetuate the practice. Similarly, as shown by the variable "gender gap", children of women with higher levels of autonomy have a lower risk of being 
circumcised. The same effect is observed in relation to the mother's age at marriage: the study shows that, other factors being equal, the extremely vulnerable position of women married early is linked to a greater circumcision risk for their daughters. This finding is particularly evident in the Egyptian and Senegalese contexts while the impact is lower, although still present, in Burkina Faso, where positive family wealth conditions are more likely to play a protective role, especially among the children of cut mothers.

Another crucial risk factor is the "family environment" in terms of physical location (rural vs. urban) but especially regarding the prevalence of circumcised women in the area of residence. According to the modernization approach, kinshipbased communities with limited cultural diversity and linked to a traditional economy are more likely to be found in rural areas. Urban settings, after all, offer families and individuals the opportunity to cope with multiple practicing and non-practicing reference groups, facilitating opinion changes regarding about the practice (Unicef, 2013). Moreover, consistent with the Convention Theory, the presence of a higher number of uncut daughters at the normative age is a crucial aspect, especially in areas characterized by an overall high prevalence of cut mothers such as Egypt and Burkina Faso.

Finally, the model confirms that in Egypt and Burkina Faso the daughters of Muslim women have a higher risk of being circumcised than the daughters of mothers practicing other religions.

The model also controls for the estimated residual correlation among daughters of the same mother (given as rho in table 2). The model shows a very high correlation for daughters of the same families especially in Burkina Faso $(r h o=0.8)$ and Senegal $(r h o=0.7)$, suggesting a high dependence among the survival times to FGC for children of the same mother after controlling for the observed dimensions. In Egypt where the practice is more widespread, the dependence exists but is less pronounced $(\mathrm{rho}=0.3)$.

\section{Discussion and conclusion}

The analysis highlights common ground regarding the intergenerational continuation of FGC in three very different contexts. These results may be used to strategically inform abandonment campaign efforts and also identify possible stakeholder groups and their capacity for change. The first point emerging from the analysis is that the intergenerational continuation of FGC is decreasing, even if at varying rates, in all three countries. Younger daughters are less at risk compared to their older siblings resulting from the promulgation of laws or specific plans to fight the practice that are creating better conditions for the protection of girls.

The study also confirms that the daughters of uncircumcised mothers are at virtually no risk of being circumcised themselves ${ }^{8}$ (Hayford, 2005; Morison et al., 200I). This means that policies aimed at changing social norms are also creating a virtuous circle: for each uncircumcised child, a risk-free thirdgeneration is projected.

As in other studies (Afifi, 2009; Tostan, 1999; Yount, 2002) and according to the feminist approach, female autonomy has a relevant impact as empowered women are potentially more open to the acceptance of new social rules. This confirms the empirical findings of holistic campaign evaluation reports indicating that broad policies aimed at improving women's conditions have an indirect positive effect on the intergenerational continuation of FGC and that these efforts are most effective and well received when aimed at assisting the community with other challenges (Berg and Denison, 2013). Despite its strong symbolic value and traditional meaning, FGC should not be treated as a separate topic from that of gender equality and community empowerment. Our study also confirms the key importance of the Convention Theory approach: in fact, girls living in communities with a low number of cut girls are at a significantly lower risk of being cut themselves, even if they have a circumcised mother or live in a country with a high overall FGC prevalence.

A special consideration with respect to the effect of religion: in order to hasten the decline of the practice, clerics would need to play an active role in supporting eradication policies and correcting information about the links between religion and FGC. The role of religious leaders, for example in Egypt and Burkina Faso, where Muslim clerics support of tradition combined with statements not clearly opposed to the practice, may have slowed the decline among Muslims. In contrast, strong opposition by Christian associations to the traditional practices may have helped to significantly change the perceived correlation of the practice with religion, accelerating the reduction within the Christian population (Baya, 201I;Von der OstenSachen and Uwer, 2007; Yount, 2004; El- Gibaly et al., 2002).

While this study highlights the key role of peer groups and female empowerment in the 
discontinuation of FGC, recent analysis of campaigns across African countries and particularly in Egypt, Senegal and Burkina Faso, underline that despite the overall good outcomes of a holistic approach, the success of a community-led programme in one village may not be paralleled in neighboring villages (Johansen et al., 20I3; Berg and Denison, 20I3).

Comparative national level studies such as ours show key factors related to FGC continuation and indicate the most appropriate program elements and theoretical basis. However, a micro level analysis of the community's social and religious factors should be regarded as a key further step because the effectiveness of these steps really requires an indepth understanding of the target population's beliefs, attitudes, values, knowledge, and past behaviors.

\section{Notes}

I In 1990 the Inter-African Committee on Traditional Practices Affecting the Health of Women and Children adopted the term 'female genital mutilation' to denote all of those practices, a terminology also shared in 1991 by the World Health Organization (WHO, 2008). However, as objections have been raised to this terminology (Eliah, 1996) the more culturally sensitive term 'female genital cutting' has become widely used among researchers and international development agencies (Unicef, 20I3). This term is also used in the Demographic and Health Survey (DHS) program and will be adopted, along with its acronym, throughout this paper when referring to the practice. Occasionally terms such as "circumcision", "cutting" or 'excision' are employed for easier reading.

2 The intramarryng community is defined as a group of persons whose membership is determined by the acceptance of certain requirements and standards that make individuals marriageable. (Unicef-IRC, 20I0: vi).

${ }^{3}$ The Stata code for this variable is available from the author's on request

${ }^{4}$ A detailed chronology of actions taken against FGC in the three countries from 1920 until the 2010s is reported in Unicef (2013:10-13).

${ }^{5}$ These descriptive statistics are different from those published in each country report since our sample includes only mothers of daughters.

${ }^{6}$ In these results it should be taken into account, especially for Burkina Faso where the Government has systematically enforced the law on FGC. Part of the variation may be due to voluntary underreporting (Unicef, 20I3).
7 The discrete time survival function is the probability of not experiencing the event by the time t $S_{t}=\operatorname{Pr}(T>t)$. The discrete time hazard is defined as the conditional probability that the event occurs at time $t$, given that it has not yet occurred: $h_{t}=\operatorname{Pr}(T=t \mid T>t-1)=\operatorname{Pr}(T=t \mid T \geq t)$.

${ }^{8}$ It should be mentioned that certain studies have highlighted a growth, albeit modest, in the diffusion of the practice in African regions where previously it was absent (Dorkenoo and Elworthy, 2006; Boyle et al., 2002).

\section{Bibliography}

Afifi, M. 2009. "Women's Empowerment and the Intention to Continue the Practice of Female Genital Cutting in Egypt“ Arch. Iran. Med. 12, (2): 154-60.

Andro, A., Lesclingand M., Cambois E., and Cirbeau C., (2009) : Excision et Handicap (ExH): Measure des lesions et traumatismes et évaluation des besoins en chirurgie réparatrice -Volet quantitatif du projectExH. Paris.

Althaus, F.A. 1997. "Female Circumcision: Rite of Passage or Violation of Rights?" International Family Planning Perspectives 23:130-33.

ANSD and ICF International (2012): Enquête Démographique et de Santé à Indicateurs Multiples au Sénégal (EDS-MICS) 2010-20II. Calverton, Maryland, USA: ANSD et ICF International.

Baya B., 201I "Excision et comportement sexuel des femmes au Burkina Faso" African Population Studies 25,(2): 646-679.

Bicchieri, C., (2005): The Grammar of Society: Nature and dynamics of social norms. Cambridge: Cambridge University Press.

Boyle E.H., McMorris B. and Gómez M. 2002 "Local Conformity to International Norms: The Case of Female Genital Cutting" International Sociology 17:533.

Caldwell, J. C. and Caldwell, P. 1993. "The nature and limits of the sub-Saharan African AIDS epidemic: Evidence from geographic and other patterns" Population and Development Review 19: 817-848.

Campbell M., Sahin-Hodoglugil N.N., and Potts M. 2006. "Barriers to Fertility Regulation: A Review of the Literature"' Stud. Fam. Plann. 37, (2): 8798.

CEPDA - Center for Population and Development Activities (2004): Female Genital Mutilation Abandonment in Egypt: Program Manual. Cairo: CEPDA Egypt. 
Dalal K., Lawoko S. and Jansson B. 2010. "Women's attitudes towards discontinuation of female genital mutilation in Egypt" J.Inj.Viol.2 (I): 4I-47

Denniston G.C., Mansfield Hodgers F. and Fayre M. (1999): M. Male and Female Circumcision. Medical legal and ethical considerations in pediatric practice. New York: Kluwer Academic/Plenum Publishers.

Diop N.J., Askew I. (2006) Strategies for encouraging the Abandonment of Female Genital Cutting: Experiences from Senegal, Burkina Faso and Mali in Abusharaf R.M. (ed.). Female Circumcision: Multicultural Perspectives. University of Pennsylvania Press.

Diop N.J., Congo Z., Ouédraogo A., Sawadogo A., Saloucou L. and Tamini I. (2008): Analysis of the Evolution of the Practice of Female Genital Mutilation/Cutting in Burkina Faso. Population Council.

Dorkenoo, E. and Elworthy, S. (2006): Female genital mutilation. Hurst.

El-Gibaly O., Ibrahim B., Mensch B.S. and Clark W.H. 2002. "The decline of female circumcision in Egypt: evidence and interpretation" Soc. Sci. Med. 54: 205-220.

El-Zanaty, F., and Way A, (2009): Egypt Demographic and Health Survey 2008. Cairo: Ministry of Health, El-Zanaty and Associates, and Macro International.

Farina, P. (ed.) 2010. Indagine sulla presenza nel territorio lombardo di popolazione a rischio in relazione alla salute sessuale e riproduttiva e alle mutilazioni genitali femminili. Milan: Irer.

Hayes, R.O. 1975. "Female Genital Mutilation, Fertility Control, Women's Roles, and the Patrilineage in Modern Sudan: A Functional Analysis." American Ethnologist 2:617-33.

Hayford S. 2005. "Conformity and Change: Community Effects on Female Genital Cutting in Kenya" J Health Soc Behav, 46,(2): I2I-I40.

Hayford S. and Trinitapoli J. 20II. "Religious Differences in Female Genital Cutting:A Case Study from Burkina Faso" J Sci. Study Relig. 50,(2):252-27I.

INSD and ICF International (20/2): Enquête Démographique et de Santé et à Indicateurs Multiples du Burkina Faso 20I0. Calverton, Maryland, USA : INSD et ICF International.

Leye E., Deblonde J., García-Añón J., Johnsdotter S., Kwateng-Kluvitse A., Weil-Curiel L. and Temmerman M., 2007. "An analysis of the implementation of laws with regard to female genital mutilation in Europe" Crime, Law and Social Change 47, (I) I-3I.

Jensen R. and Thornton R. 2003. "Early female marriage in the developing world" Gender\& Development, II,(2): 9-I9.

Johansen R.E., Diop N.J., Laverack G., and Leye E., "What Works and What Does Not: A Discussion of Popular Approaches for the Abandonment of Female Genital Mutilation" Obstetrics and Gynecology International, vol. 2013, Article ID 348248.

Mackie G. and Lejeune J. (2009): Social dynamics of abandonment of harmful practices: a new look at the theory. Florence: UNICEF Innocenti Research Centre.

McCloud P.A., Aly S., Goltz S. (2003) Promoting FGM Abandonment in Egypt: Introduction of Positive Deviance. Center for Population and Development Activities (CEPDA).

Morison, L. ,Scherf, C. , Ekpo, G. , Paine, K. , West, B. , Coleman, R. and Walraven, G. 200I. "The long-term reproductive health consequences of female genital cutting in rural Gambia: a community-based survey" Trop Med Int Health 6,(8): 643-53.

Nour, N.M. (2005) "Number of women, girls with or at risk for female genital cutting on the rise in the United States" Press Release. African Women's Health Centre, Brigham and Women's Hospital: Boston.

Phillips, J. F., Bazle Hossain M. and Arends-Kuenning M. 1996. "The long-term demographic role of community-based family planning in rural Bangladesh" Stud. Fam. Plann 27(4): 204-219.

Population Council (20II): National Efforts toward FGM-free Villages in Egypt: The Evidence of Impact. Working Paper No. 22, New York.

Population Council (2003): Female Circumcision in Indonesia: Extent, implications and USAID, Jakarta, 2003.

Population Council, Frontiers in Reproductive Health (2005): Female genital cutting. Community education program scaled-up in Burkina Faso. OR Summary No. 55; Washington, D.C.

Population Council, GTZ, TOSTAN (2004): The TOSTAN Program. Evaluation of a Community Based Education Program in Senegal.

Roald, A.S. (200I): Women in Islam: the Western experience. London: Routledge.

Shell-Duncan, B. (2008). "From Health to Human Rights: Female Genital Cutting and the Politics of 
Intervention" American Anthropologist II0(2): 225-236.

Shell-Duncan, B. and Hernlund Y. (eds.) 2000. Female "circumcision" in Africa: Culture, controversy, and change. Boulder: Lynne Riener Publishers.

TOSTAN (1999): Breakthrough in Senegal-the process that ended female genital cutting in 31 villages. Dakar, Senegal: TOSTAN.

UN General Assembly (20I2): Intensifying global efforts for the elimination of female genital mutilations (accessed October 24 ${ }^{\text {th }}, 2013$ ) http://www.un.org/ga/search/view_doc.asp?symb ol $=\mathrm{A} / \mathrm{RES} / 67 / \mathrm{l} 46$

UNICEF (20I3): Female genital mutilation/cutting: a statistical overview and exploration of the dynamics of change. New York: UNICEF.

Unicef (2005): Female Genital Mutilation/Cutting: A statistical exploration, New York: UNICEF.

Unicef-IRC 2005 "Changing A Harmful Social Convention: Female Genital Mutilation/Cutting"Innocenti Digest 12 Florence: UNICEF.

Unicef-IRC (2010): The Dynamics of Social Change Towards the Abandonment of Female Genital Mutilation/Cutting in Five African Countries. Florence: UNICEF.
UNDP (20I2): Human Development Index Report. New York: UNDP.

UNFPA (20II): Project Embera-wera: An experience of culture change to eradicate female genital mutilation in Colombia - Latin America. UNFPA.

Von der Osten-Sacken T. and Uwer T., 2007 "Is Female Genital Mutilation an Islamic Problem?"Middle East Quarterly, Winter: 29-36.

Yoder, P. S., Abderrahim N. and Zhuzhuni A. (2004): Female Genital Cutting in the Demographic and Health Surveys: A Critical and Comparative Analysis. DHS Comparative Reports No 7. Calverton, Maryland: ORC Macro.

Yount K.M. 2002.“Like Mother, Like Daughter? Female Genital Cutting in Minia, Egypt" J Health SocBehav 43,(3):336-58.

Yount K.M. 2004. "Symbolic Gender Politics, Religious Group Identity, and the Decline in Female Genital Cutting in Minya, Egypt" Social Forces 82, (3): 1063-1090.

WHO (2008): Eliminating Female genital mutilation. An interagency statement, New York: WHO. 